\title{
NEW ANTICOAGULANTS AS \\ THROMBOPROPHYLAXIS AFTER TOTAL HIP OR KNEE REPLACEMENT
}

Vida Hamidi, Tove Ringerike, Gunhild Hagen, Åsmund Reikvam, Marianne Klemp

Norwegian Knowledge Centre for the Health Services

Objectives: Due to a high risk of thromboembolism in patients undergoing major orthopedic surgery, it has become standard practice to give thromboprophylactic treatment. We assessed the relative efficacy and cost-effectiveness of two new oral anticoagulants, rivaroxaban and dabigatran, relative to subcutaneous enoxaparin for the prevention of thromboembolism after total hip replacement (THR) and total knee replacement surgery (TKR).

Methods: We conducted a systematic review of the literature to assess efficacy and safety, and evaluated quality of documentation using GRADE. Cost-effectiveness was assessed by developing a decision model. The model combined two modules; a decision tree for the short-term prophylaxis and a Markov model for the long-term complications and survival gain. Results: For rivaroxaban compared with enoxaparin, we found statistically significant decreases in deep vein thrombosis, but also a trend toward increased risk of major bleeding. For mortality and pulmonary embolism there were no statistically significant differences between the treatments. We did not find statistically significant differences between dabigatran and enoxaparin for our efficacy and safety outcomes. Assuming a willingness to pay of EUR62,500 per QALY, rivaroxaban following THR had a probability of 38 percent, and enoxaparin following TKR had a probability of 34 percent of being cost-effective. Clinical efficacy had the greatest impact on decision uncertainty.

Conclusions: Dabigatran and rivaroxaban are comparable with enoxaparin following THR and TKR regarding the efficacy and safety outcomes. However, there is great uncertainty regarding which strategy is the most cost-effective. More research on clinical efficacy of rivaroxaban and dabigatran is likely to change our results.

Keywords: Venous thromboembolism, Arthroplasty, Anticoagulants, Health technology assessment, Economic evaluation

Venous thromboembolism (VTE) is a common complication after orthopedic surgery, causing considerable morbidity, mortality, and resource usage. VTE is the presence of a blood clot that blocks a blood vessel within the venous system. It includes deep vein thrombosis (DVT) and pulmonary embolism (PE). Furthermore, patients with DVT may go on to develop postthrombotic syndrome (PTS), a painful disabling condition that carries an increased risk of recurrent DVT.

Patients undergoing major lower extremity orthopedic surgery are at high risk for VTE (1). The results of previous studies have indicated that the development of VTE almost doubled the costs of inpatient care for patient undergoing major orthopedic surgery (2).

Due to high risk of VTE in elective hip- or knee replacement surgery, it has become standard care to offer thromboprophylactic treatment $(3 ; 4)$. For many years, subcutaneous low molecular weight heparins (LMWHs) like enoxaparin have been the primary choice for thrombosis prevention after major orthopedic surgery. Recently, two new anticoagulants, rivaroxaban and dabigatran, have been suggested as possible alternative prophylactic treatments. In contrast to LMWH, which is given subcutaneously, both these new drugs can be given orally. Overall,

The authors are grateful to Marita Heintz, Hege Kornør, Ingvil Sæterdal, Ingvild Kirkehei, Pål Borgen, Ivar Sønbø Kristiansen, Torbjørn Wisleff, and Vigdis Laurak for their input and support throughout the project. according to the summary of product characteristics for the included interventions, the recommended treatment duration is between 28 and 35 days for patients having major hip surgery (THR), and 7-14 days for patients having major knee surgery (TKR) (5).

Major orthopedic surgery is one of the most common surgeries among the elderly. Due to a large and increasing number of major orthopedic surgeries and the debate concerning a possible change in current practice, it was of great interest to explore the health and cost consequences of replacing the convention treatment with LMWH by new anticoagulants as thromboprophylaxis after THR or TKR. The objectives of this study were to assess the relative efficacy, safety and cost-effectiveness of rivaroxaban and dabigatran compared with LMWH (i.e., enoxaparin) for the prevention of thromboembolism after THR and TKR.

\section{METHODS}

Clinical Efficacy

We searched systematically for systematic reviews (SRs) and randomized controlled trials (RCTs) in Ovid Embase, Ovid Medline, Cochrane Library, and Centre of Reviews and Dissemination from inception to July 2010 (SR) or 2009 to September 2010 (RCT). We used a combination of keywords and text words relating to orthopedic surgery and the relevant drugs, 


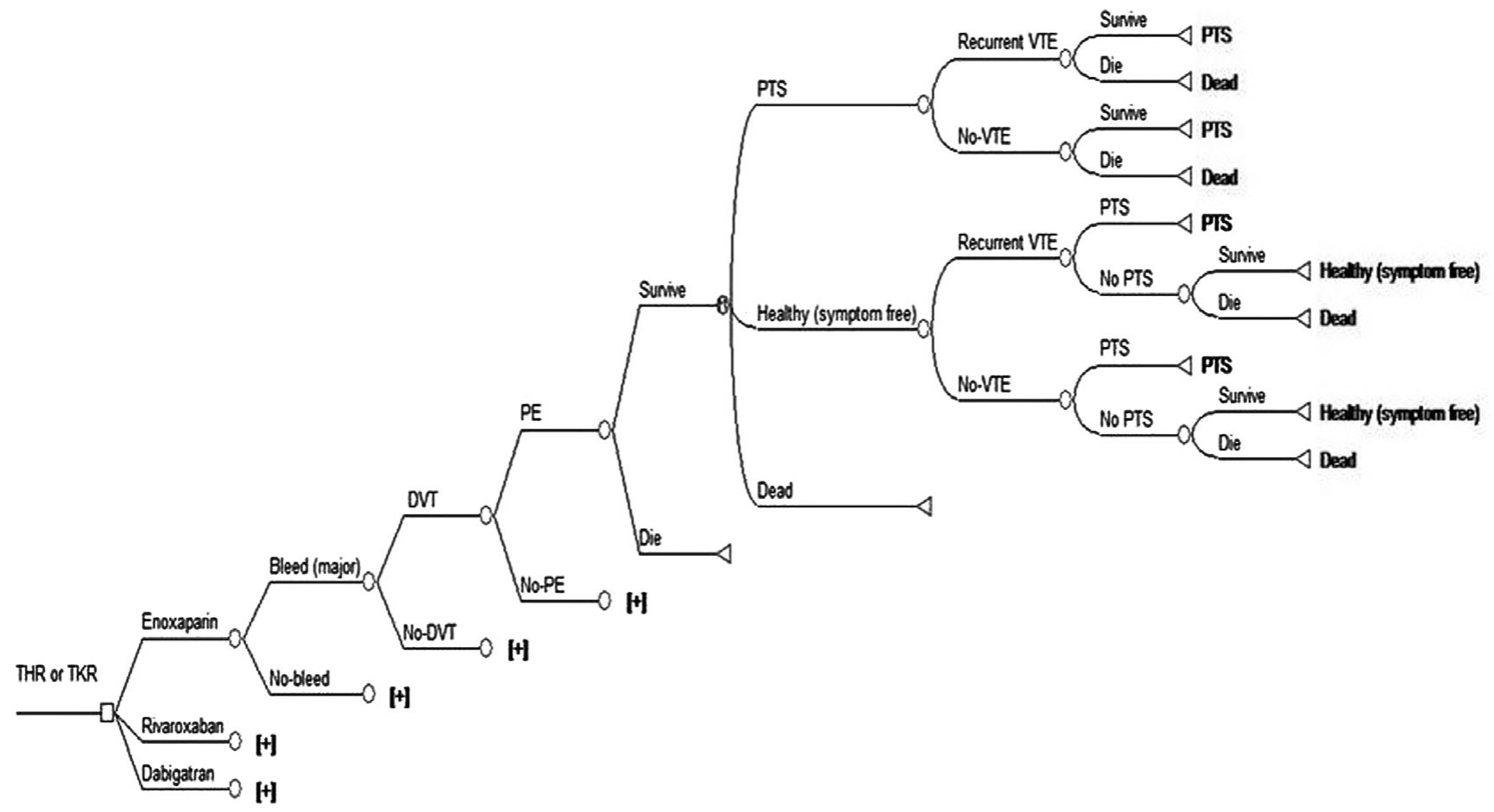

Figure 1. Model structure (the branches marked with plus signs are similar to their respective opposite branch). THR, total hip replacement; TKR, total knee replacement; DVT, deep-vein thrombosis; PE: pulmonary embolism; PTS: post-thrombotic syndrome; VTE: venous thromboembolism.

and finally added filters for SR or RCT if available in the database (Supplementary Table 1, which can be viewed online at www.journals.cambridge.org/thc2013096). In addition, we manually searched reference lists from the included publications, and Web sites for other published HTA reports (INAHTA and NIHR). Two reviewers independently screened abstract and title in all citations identified against predefined eligibility criteria. Possible relevant articles were retrieved in full text. Publications were included if they were SRs or RCTs comparing new anticoagulants to traditional treatment with LMWT for patients undergoing THR or TKR. Our primary outcomes were mortality, DVT, PE, PTS, major bleeding, and other adverse events. For evaluation of bleeding, we have focused on major bleedings because they were defined in the included studies. The definition varied somewhat among the studies; however, all the studies defined a severe bleeding if it involved a critical site (intracranial, intraocular, intraspinal, or retroperitoneal bleeding). Length of stay in hospital, need for re-operations, re-admission to hospital, infections, ability to work, and quality of life were considered as secondary outcomes.

The quality of the included publications were assessed independently by two reviewers using the Cochrane method of Risk of Bias assessment for RCTs or a check list for SRs (6). Data were collected from the SRs. In cases where the SRs had pooled data into composite end points or mixed populations, we extracted data from the identified RCTs to fit our outcomes. All data were extracted by one person, and controlled by a second person for accuracy.
When appropriate, we pooled data by meta-analyses with the software; RevMan 5. We used a random-effects model calculating relative risks (RR) with 95 percent confidence intervals. As far as possible, our analyses were performed according to the principle of intention-to-treat populations. For the end points related to efficacy, PE and DVT, we included treatment with all doses, but only treatment duration comparable to the generally recommended treatment duration after THR and TKR. However, for the end points related to safety, mortality, and major bleeding, we included all data irrespective of treatment time and dose. This was to ensure that all safety information become easily accessible. The quality of the documentation for each end point was evaluated using the Grading of Recommendation, Assessment, Development, and Evaluation (GRADE) tool (7).

Any disagreements after independent assessments regarding literature selection, data extraction, and quality assessment were dissolved by discussion or by consulting a third reviewer.

\section{Cost-Effectiveness}

To assess the cost-effectiveness of the alternative thromboprophylactic interventions, we made a decision model (Figure 1). The model combined two modules; a decision tree for the shortterm prophylaxis (acute phase; 90-day postsurgery time horizon) and a Markov model for the long-term complications and survival gains (lifetime horizon). DVT, PE, and major bleeding events were modeled for the acute phase. Patients entered the Markov model at the end of the acute phase. The chronic phase model contained three health states "symptoms-free 
patient," "PTS," and "Dead" with cycle length of one year. The two surgery types, THR and TKR, were modeled separately to reflect differences in the underlying risk of developing DVT, PE, and major bleeding.

The model calculated quality-adjusted life-years (QALYs) and life time costs related to the different strategies. The results of economic evaluations were expressed as incremental costeffectiveness ratios (ICERs; equation 1) and net health benefit (NHB; equation 2) by incorporating the society threshold willingness to pay for an additional unit of health benefit (WTP).

1. ICER $=$ Incremental costs / Incremental QALYs (Eq. 1)

2. NHB $=$ Incremental QALYs - (Incremental costs / WTP) (Eq. 2)

In the absence of an explicit threshold value for costeffectiveness in Norway, we assumed a value of EUR62,500 per QALY gained as a best possible temporary estimate. An intervention can in other words be considered cost-effective if it yields a positive NHB.

Analysis was carried out from a healthcare payer perspective. Costs and QALYs were discounted at a rate of 4 percent per annum.

\section{Model Probabilities}

The incidence of symptomatic DVT and PE in patients undergoing THR and TKR are based on a Norwegian study (8). LMWH was given to all patients while hospitalized in that study. The baseline risk of major bleeding following thromboprophylaxis were taken from a review article that reported major bleeding rates in patients treated with enoxaparin during THR and TKR trials (9). These baseline probabilities were multiplied by the estimate of relative efficacy of each intervention versus conventional treatment with enoxaparin.

The annual risk of recurrent VTE and developing PTS were estimated from a prospective study of the long-term follow-up of acute VTE over a 5-year period (10). The risk of PTS was assumed to begin after day 90. Patients who had no VTE event in the postsurgical period were assumed to be at the same risk for a VTE event and PTS as the general population $(11 ; 12)$.

For calculating the risk of death in the acute phase, we collected age and gender specific Norwegian all-cause mortality data from Statistics Norway (13). These data were multiplied by the relative risk of all-cause mortality from meta-analyses of the included articles in our systematic review for acute phase and the relative risk of death from VTE for the postoperative phase (10). The model probabilities are presented in Table 2.

\section{Clinical Outcomes}

Efficacy estimates and Grading are presented in Table 1. We incorporated the GRADE assessments into the model by assigning probability distributions related to the quality of the evidence, with a wider distribution for the lower quality documentation. For efficacy estimates based on high quality evidence, probabil- ity distributions were based on 95 percent confidence intervals. For moderate, low or very low quality results, we have used confidence intervals of respectively 90 percent, 80 percent, and 70 percent which reflects that we have less trust in the data (14).

\section{Costs}

All costs were expressed in 2010 Norwegian kroner and converted into Euros (EUR1.00 $\approx$ NOK8.01) and presented in Table 2. The cost of thromboprophylaxis after hospital discharge is based on maximum pharmacy retail prices. In-hospital drug costs are calculated based on the price list we received from the Drug procurement cooperation. Administration cost related to injection of enoxaparin was included in the model based on the following assumptions: it is most likely that patients are discharged to rehabilitation centers (65-95 percent) (15) and will receive enoxaparin injections in these centers (therefore, these injection costs were not included in the analysis). Among the patients discharged to their homes, we assumed that 5-13 percent of patients require nurse assistance during the period after hospital discharge. The cost of one nurse visit was estimated based on the average of administration cost of private and municipal nurse visit at home.

The costs of treating bleeding, DVT, or PE events were based on prices within the Norwegian Diagnosis Related Group (DRG) system (16). For the cost of diagnosing DVT or PE, we assumed one physician visit and one diagnostic investigation (for DVT: ultrasound and venography [for 8 percent of patients] (17); and for PE: spiral computed tomography and chest radiography). The cost of physician visits and diagnostic investigations were obtained from the price list for cost per outpatient clinic consultation and procedure (18).

The cost of PTS was estimated based on the cost of acute and chronic PTS reported by Bjorvatn and Kristiansen (19). We have assumed that the cost of diagnosing PTS is the difference between the cost related to the acute phase and the later chronic phase. The cost of diagnosing PTS was included in the Markov model in the first year only.

\section{Utilities}

The literature search emphasized a lack of good-quality utility data for this population. Therefore, the utility values are based on different sources (Table 2).

The baseline health state value for patients who had THR and TKR without complications and the utility for one year after the operation were taken from Räsänen and co-workers (20).

Utility value for symptomatic DVT, PE, and recurrent VTE were derived from Haentjens et al. 2004 (21). The duration of symptomatic DVT and PE was estimated to 3 months and 6 months, respectively. These utility values were adjusted by multiplying them by the values reported by Räsänen and co-workers (20) because no distinction was made between complications following THR and TKR. 
Table 1. Efficacy and Safety Results for Dabigatran and Rivaroxaban Compared to Enoxaparin

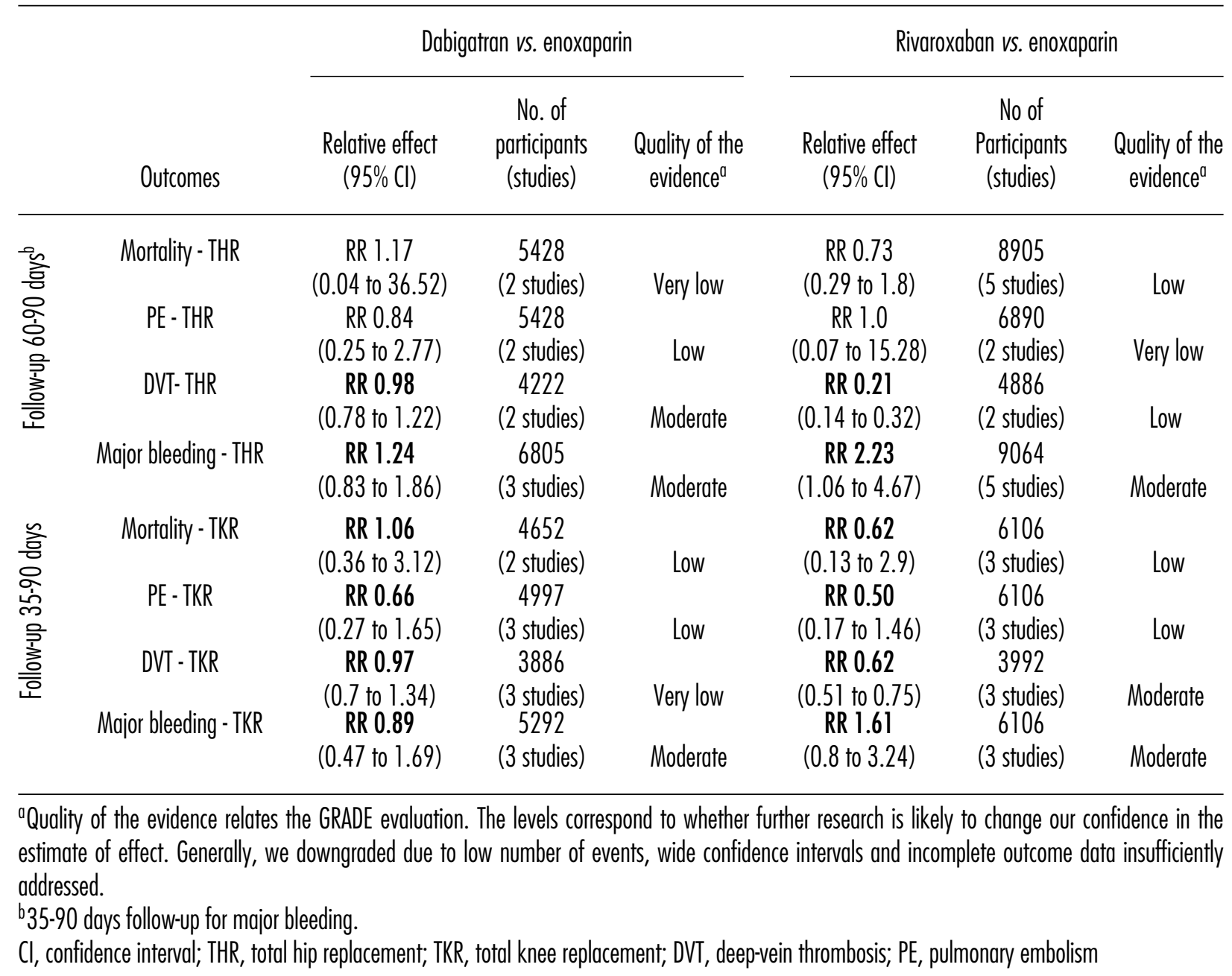

For major bleeding, we have used utility values for central nervous system bleeding in our model. Utility values for major bleeding and PTS were estimated based on values reported by Lenert and Soetikno (22) and adjusted for the base-line utilities (20).

\section{Sensitivity Analysis}

To explore the consequences of uncertainties in the basecase parameter values, we performed a probabilistic sensitivity analysis (PSA) in which all input parameters were randomly drawn from probability distributions and the model was run 10,000 times. For probabilities and utility estimates, the betadistributions were constructed on plausible ranges for parameters. For cost, we modeled gamma-distributions where limits were within a 30 percent of the base-case value. Efficacy and safety parameters were assumed to have a log-normal distribution.

PSA was presented by cost-effectiveness acceptability frontier curves (CEAFs), which have been recommended for decision analyses involving more than two interventions (23). The CEAFs showed the decision uncertainty surrounding the optimal strategy at different values of WTP.

We also performed an analysis of the expected value of perfect information (EVPI) to explore the uncertainty surrounding specific groups of parameters and to show which groups of input parameters it is most useful to conduct further research on. The EVPI for the parameter or group of parameters is the difference between the expected net benefit with perfect (additional) information and the expected value with current information about the parameter(s) (24).

We could not identify reliable data that could show the effect of the different methods of administrating the medication on patients' utility. Thus, the possible disutility associated with injections was not included in the base-case analyses. Because part of the purpose of the new anticoagulants was the oral administration, we performed scenario analyses to test the assumption of the possible disutility associated with the subcutaneous administration of enoxaparin in our model. We adjusted the baseline health state value with 0.5 percent (expert opinion) for the duration patients were treated with enoxaparin as thromboprophylaxis after THR and TKR. 
Table 2. Probabilities, Cost of Prophylaxis and of Thromboembolic Events, and Utilities Values Used in the Model

\begin{tabular}{|c|c|c|c|c|c|c|c|}
\hline & & \multicolumn{3}{|c|}{ Total hip replacement (THR) } & \multicolumn{3}{|c|}{ Total knee replacement (TKR) } \\
\hline \multirow{11}{*}{ 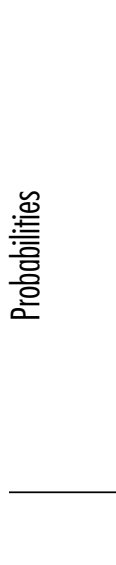 } & DVTa $^{(8)}$ & \multicolumn{3}{|c|}{0.016} & \multicolumn{3}{|c|}{0.016} \\
\hline & $\mathrm{PE}^{\mathrm{a}}(8)$ & \multicolumn{3}{|c|}{0.011} & \multicolumn{3}{|c|}{0.011} \\
\hline & Major bleeding ${ }^{a}(9)$ & \multicolumn{3}{|c|}{0.017} & \multicolumn{3}{|c|}{0.005} \\
\hline & Developing PTS: year 1 (10) & \multicolumn{3}{|c|}{0.180} & \multicolumn{3}{|c|}{0.180} \\
\hline & Developing PTS: year $2^{\mathrm{b}}$ & \multicolumn{3}{|c|}{0.131} & \multicolumn{3}{|c|}{0.131} \\
\hline & Developing PTS: year $3^{b}$ & \multicolumn{3}{|c|}{0.068} & \multicolumn{3}{|c|}{0.068} \\
\hline & Developing recurrent VTE: year $1-2(10)$ & \multicolumn{3}{|c|}{0.090} & \multicolumn{3}{|c|}{0.090} \\
\hline & Developing recurrent VTE: year $3+^{b}$ & \multicolumn{3}{|c|}{0.054} & \multicolumn{3}{|c|}{0.054} \\
\hline & PTS for patients who had no VTE event (11) & \multicolumn{3}{|c|}{0.0008} & \multicolumn{3}{|c|}{0.0008} \\
\hline & Recurrent VTE for patients who had no VTE event (12) & \multicolumn{3}{|c|}{0.0014} & \multicolumn{3}{|c|}{0.0014} \\
\hline & & Dabigatran & Rivaroxaban & Enoxaparin & Dabigatran & Rivaroxaban & Enoxaparin \\
\hline \multirow{10}{*}{ 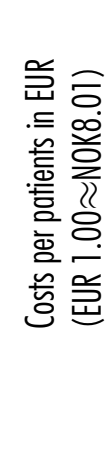 } & Cost of medicament Inpatient ${ }^{d}$ & $16^{\mathrm{e}}$ & $21^{\dagger}$ & \multirow{10}{*}{$\begin{array}{c}8^{9} \\
140 \\
1,296\end{array}$} & $12^{\mathrm{e}}$ & $15^{f}$ & \multirow{16}{*}{$\begin{array}{c}6^{9} \\
48 \\
185\end{array}$} \\
\hline & Cost of medicament outpatient (5) & 145 & 186 & & 31 & 65 & \\
\hline & Drug administration (outpatient) $)^{h}(41 ; 42)$ & & & & & & \\
\hline & Major bleeding (16) & & 3,068 & & & 3,068 & \\
\hline & Treatment DVT (16) & & 2,850 & & & 2,850 & \\
\hline & Treatment PE (16) & & 6,331 & & & 6,331 & \\
\hline & DVT diagnosis (post discharge) (18) & & 254 & & & 254 & \\
\hline & PE diagnosis (post discharge) (18) & & 391 & & & 391 & \\
\hline & Treatment PTS (19)i & & 934 & & & 934 & \\
\hline & PTS diagnosis (19) ${ }^{i}$ & & 700 & & & 700 & \\
\hline \multirow{6}{*}{ 奒 } & No VTE event (20) & & 0.805 & & & 0.807 & \\
\hline & Symptomatic DVTi (20;21) & & 0.676 & & & 0.678 & \\
\hline & PEi $(20 ; 21)$ & & 0.612 & & & 0.613 & \\
\hline & Major bleedingi $(20 ; 22)$ & & 0.531 & & & 0.532 & \\
\hline & $\begin{array}{l}\text { No VTE event; long-term (20) } \\
\text { PTSi,k }(20 ; 22)\end{array}$ & & $\begin{array}{l}0.858 \\
0.647\end{array}$ & & & $\begin{array}{l}0.841 \\
0.735\end{array}$ & \\
\hline & Recurrent VTEi $(20 ; 21)$ & & 0.721 & & & 0.706 & \\
\hline
\end{tabular}

DVT, deep-vein thrombosis; PE, pulmonary embolism; VTE, venous thromboembolism; PTS, post-thrombotic syndrome.

aIn the model, these baseline probabilities were multiplied by the estimate of relative efficacy of each intervention versus conventional treatment with enoxaparin.

bestimated based on Prandoni et al 1997 (10).

'Length of stay: total hip replacement: 5-12 days; total knee replacement: 3-10 days.

din-hospital drug costs are calculated based on the price list.

${ }^{\text {e} T w o ~} 110 \mathrm{mg}$ tablets per day, except on day 1.

f $10 \mathrm{mg}$ per day.

$940 \mathrm{mg}$ per day.

helated to injection of enoxaparin. Among the patients discharge to their homes, assumed 5-13\% required nurse assistance (43).

'Costs were adjusted from 2003 to 2010 kroner by using the Norwegian consumer price index. http:/www.ssb.no/vis/kpi/kpiregn.html

iThese utility values were adjusted based on the baseline values reported by Räsänen et al 2007 (20).

kMean PTS utilities are adjusted for the proportion with mild and severe PTS based on Ashrani et al 2009 (44). 


\section{a: THR}

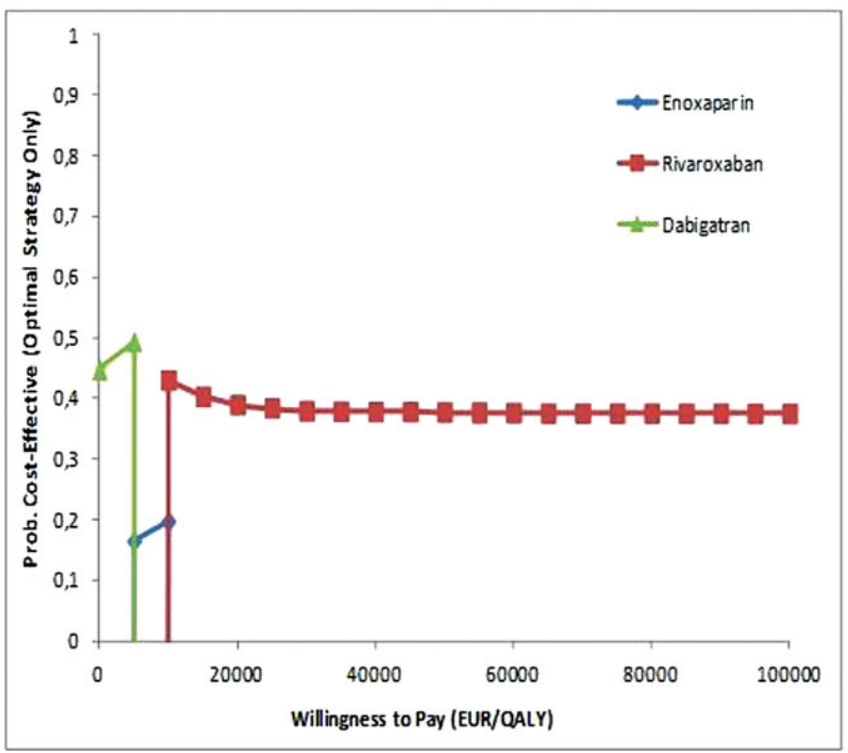

b: TKR

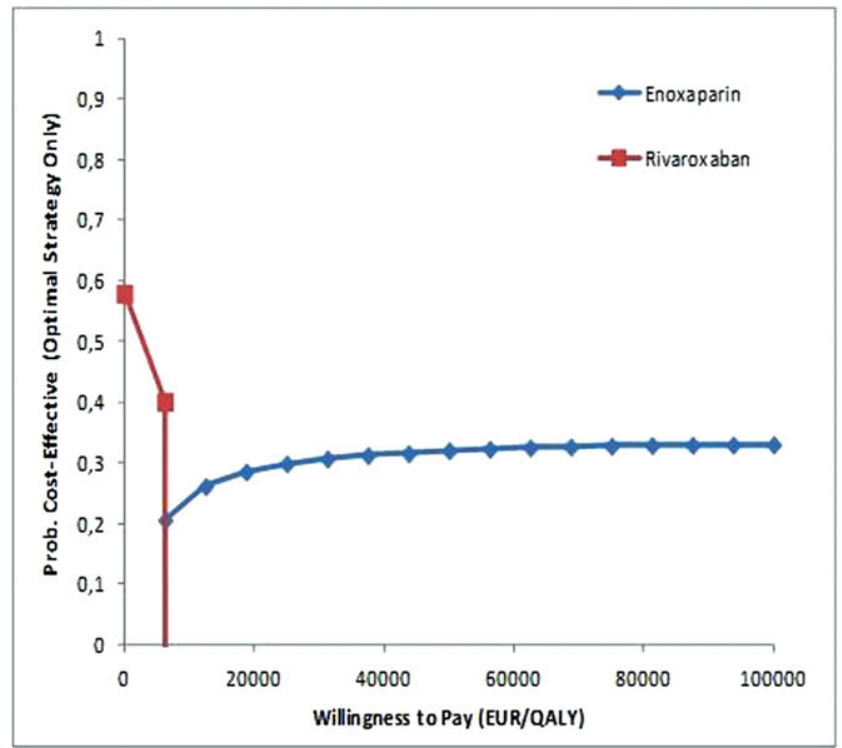

Figure 2. Results of the probabilistic analysis (CEAF) which show the best choice at different levels of willingness to pay; a: total hip replacement (THR), and b: total knee replacement (TKR).

\section{RESULTS}

\section{Clinical Effectiveness}

Our search for literature identified 909 references. Based on the inclusion criteria, we finally included two SRs and two newly published RCTs (Supplementary Table 2, which can be viewed online at www.journals.cambridge.org/thc2013097, and Supplementary Figure 1, which can be viewed online at www.journals.cambridge.org/thc2013098). Among the included studies, there were one SR and two RCTs identified by hand search. We did not identify studies that directly compared dabigatran with rivaroxaban. Data for PTS or any of our secondary outcomes were not reported.

The doses and treatment duration varied from study to study. In general, dabigatran and rivaroxaban were tested in several doses with treatment start after surgery, while enoxaparin treatment started the night before surgery (Supplementary Table 3, which can be viewed online at www.journals.cambridge. org/thc2013099, and Supplementary Table 4, which can be viewed online at www.journals.cambridge.org/thc2013100).

\section{Efficacy of Dabigatran versus Enoxaparin}

We included one SR (4), containing four RCTs comparing dabigatran to enoxaparin, BISTRO (25), RE-MOBILIZE (26), REMODEL (27), and RE-NOVATE (28). In addition, we added a new RCT, RE-NOVATE II (29).

In summary, we did not find statistical significant differences between dabigatran and enoxaparin for the outcomes mortality, PE, DVT, or major bleeding. The quality of the documentation ranged from moderate to very low. Overall results are presented in Table 1.

\section{Efficacy of Rivaroxaban Versus Enoxaparin}

Based on the included SR (4) and hand search of reference lists, we included in total eight RCTs, four phase II dose-finding studies (three from the ODIX-program (30-32)), one by Eriksson and co-workers (31), and four phase III studies RECORD 1 to $4(3 ; 33-35)$.

In summary, for rivaroxaban compared with enoxaparin, we found a statistical significant decrease in DVT, but also a trend toward increased risk of major bleeding (only significant for THR). For the end points mortality and PE, there were too few events to make a conclusion with regard to potential risks. The quality of the documentation ranged from moderate to very low. Overall results are presented in Table 1.

\section{Cost-Effectiveness}

Thromboprophylactic Treatment after THR. The base-case analyses indicated that dabigatran decreased both lifetime costs (by EUR76) and effectiveness (by 0.304 QALYs) relative to enoxaparin. Rivaroxaban compared with enoxaparin, however, would yield 0.175 additional QALYs at an additional cost of EUR983 (Supplementary Table 5, which can be viewed online at www.journals.cambridge.org/thc2013101).

Probabilistic sensitivity analysis indicated great uncertainty regarding which strategy that was most likely to be cost-effective. Assuming a willingness to pay (WTP) per QALY gained of EUR62,500, the probability that rivaroxaban was the most cost-effective strategy after THR was 38 percent (Figure 2a).

\section{Thromboprophylactic Treatment after TKR}

The base-case analysis in a TKR population indicated that both dabigatran and rivaroxaban decreased lifetime cost (by 
EUR22 and EUR39, respectively) relative to enoxaparin. However, the results of our analyses showed that both dabigatran and rivaroxaban also resulted in fewer QALYs (by 0.020 QALYs and 0.018 QALYs, respectively) than enoxaparin (Supplementary Table 6, which can be viewed online at www.journals.cambridge.org/thc2013102).

Probabilistic sensitivity analysis revealed that the simulated incremental cost-effectiveness ratios (ICER) were widely spread and indicated a considerable uncertainty with regard to which strategy was most likely to be cost-effective. Assuming a WTP per QALY gained of EUR62,500, the probability that enoxaparin was the most cost-effective strategy after TKR was 34 percent (Figure $2 b$ ).

\section{Scenario Analyses}

We adjusted the baseline health state value with 0.5 percent (expert opinion) for the duration patients were treated with enoxaparin after THR and TKR. The analyses indicated that the correction factor had a very small impact on the results and the conclusion remained the same.

\section{Expected Value of Perfect Information}

The results of value of information analyses on all uncertain parameters indicated that efficacy estimates for both populations (THR and TKR) had the greatest impact on decision uncertainty, and if new research is to be undertaken then it seems that efficacy data has the biggest potential to reduce decision uncertainty (Supplementary Figure 2, which can be viewed online at www.journals.cambridge.org/thc2013103, and Supplementary Figure 3, which can be viewed online at www.journals.cambridge.org/thc2013104).

\section{DISCUSSION}

To our knowledge, this is the first study which assessed clinical efficacy and performed cost-utility analysis of dabigatran and rivaroxaban compared with conventional treatment with enoxaparin as thromboprophylaxis after THR and TKR in a lifetime perspective.

The evaluation of clinical effectiveness of new anticoagulants was based on multi-national RCTs and, therefore, the results would be generally transferable between countries. In addition, we have developed a decision model to assess the cost-effectiveness of different treatment strategies. Although the results from cost-effectiveness analyses, which is based on country specific underlying risks, resource use and unit cost, may not directly be transferable between countries, the model structure and the approach used in health economics analyses should be of interest for other researchers modeling the same research question. Moreover, we have discussed the different choices and their possible impact on the final result.

Overall, there was no clear best choice among dabigatran, rivaroxaban, and the conventional treatment with enoxaparin regarding relative efficacy. Our health economic analyses also indicated a great uncertainty regarding which strategy is the most cost-effective. More research on clinical efficacy would contribute to decrease the uncertainty surrounding the estimated ICERs.

\section{Limitations of the Study}

The quality of the evidence on efficacy and safety ranged from moderate to very low. This was mainly due to a low number of events on rare outcomes like mortality, PE and major bleeding. Hence, it is likely that further research with additional events will change the efficacy estimates.

Important end points, DVT and PE, are often difficult to diagnose. In all included studies, symptomatic DVT events were evaluated if the diagnosis was confirmed by venography. In a substantial proportion of the trials patients, venography was not performed or the interpretation of the venography was inconclusive. However, the nature and the scale of this problem seem to have been similar in all studies.

It is subject to discussion which data should be combined in a meta-analysis, especially with regard to events in the early dose-finding studies included in our safety analyses. However, the uncertainty added by pooling data across doses, may in some instances, be counteracted by the fact that the number of events increases.

Attention should also be given to the duration of treatment, in one of the trials of rivaroxaban versus enoxaparin (36), the former therapy was extended for 31-39 days while enoxaparin was given only for 10-14 days. This study design with a longer rivaroxaban treatment period might have favored rivaroxaban, and a priori one would expect lower frequency of DVT/VTE in the rivaroxaban group than in the enoxaparin group, a finding that in fact was confirmed.

Any simulation model is a simplification of real life. Therefore limitations associated with our simplistic health economic model and the cost-effectiveness analysis should be considered.

As pooled effect estimates were used, it is possible that different input in the meta-analyses like restricting to only specific doses or treatment lengths would give different effect estimates and hence, different cost-effectiveness results. This is an important notion given that the value of information analyses indicated that efficacy data have the greatest impact on decision uncertainty in our model. Moreover, we only included the most common long-term VTE complications (i.e., PTS and recurrent VTE) (37) in the postacute phase sub-model.

We performed a systematic literature search to identify the best possible evidence on utilities for our model. The search did not identify any single study or combination of studies reporting the utility values measured by a common instrument for all the events and the health states included in our model. In the lack of good-quality utility data for our study population, the utility values were therefore based on different sources and instruments, which may introduce inaccuracies in the results. However, the same approach has been used in the previous cost-utility 
analyses of thromboprophylaxis after THR or TKR $(38 ; 39)$. For major bleeding, we have used utility values for central nervous system bleeding (intracranial or spinal bleeding) in our model. This was based on assumption that treatment with anticoagulant medicaments can cause critical hemorrhage affecting the central nervous system, which will have long-term health consequences. However, focusing just on the utility related to central nervous system may be considered as a limitation of our study.

In addition, we could not identify reliable data that showed the probable effect of the different methods of administrating the medication on patients' utility. Hence, the possible advantage to patients of taking oral medication is not considered in the basecase results. However, we adjusted the baseline health state value for the duration patients were treated with enoxaparin as thromboprophylaxis after THR and TKR. The correction factor, however, had a very small impact on the results.

With regard to the uncertainty related to the quality of the efficacy documentation, we incorporated results from the GRADE evaluations into efficacy parameters in our probabilistic model by differentiating the confidence interval used (14). It is conceivable that such adaption may change the results and the uncertainty around the conclusions. Hence, our model analyses may have underestimated the cost-effectiveness of the new thromboprophylactic treatments.

\section{Comparison with Other Health Economic Studies}

We found two other studies which compared the cost and the effects of prophylaxis with the new oral anticoagulants with enoxaparin. Wolowacz and co-workers concluded that dabigatran was dominant compared with enoxaparin in both THR and TKR analyses (40). McCullagh and co-workers showed that rivaroxaban dominated both enoxaparin and dabigatran in both THR and TKR analyses (39).

Different assumptions for the estimation of clinical effectiveness may be considered as the most important cause of the differences between our results and the two other economic studies. We included and combined all relevant studies, across all doses and treatment lengths in the meta-analyses to achieve most robust data, while the two other economic evaluations $(39 ; 40)$ were only performed for a $220-\mathrm{mg}$ dose of dabigatran and $40 \mathrm{mg}$ of enoxaparin. Moreover, the results of economic analysis of rivaroxaban compared with enoxaparin for patients undergoing THR in McCullagh and co-workers study (39) were based solely on one trial (36). Because rivaroxaban therapy in this study (34) was extended for 31-39 days while enoxaparin was given only for 10-14 days, one would, therefore, expect a lower frequency of DVT in the rivaroxaban group.

Furthermore, variation in model structure (e.g., McCullagh and co-workers developed a decision-tree model with a 180 day time horizon) and differences in methodology, for example, variation in country specific costs, may also be considered as possible causes for the observed differences in the results.

\section{CONCLUSION AND POLICY IMPLICATIONS}

The efficacy and safety of dabigatran and rivaroxaban in hip and knee replacement surgery are comparable with enoxaparin. In addition, our economic analyses showed that there is a great uncertainty regarding which strategy is the most cost-effective. The results of the model analyses to explore the uncertainty surrounding each group of parameters indicated that more research on clinical end points would have the greatest impact on reducing decision uncertainty.

Intuitively, a main advantage of the new anticoagulants is the oral administration. It has been hypothesized that the subcutaneous administration of LMWHs after discharge is more cumbersome and might affect patient compliance. However, to our knowledge, the issue has not been addressed in clinical studies and it remains a hypothesis and might be considered when treatment decisions are made.

At present, there is no antidote for the new oral agents. The risk of bleeding when acute surgery (re-operations) and spinal aesthesia need to be performed on patients taking these drugs has not been sufficiently examined. Moreover, the longterm safety of the new anticoagulants is not as well known as for treatment with LMWH. There is also a lack of knowledge around potential drug interactions with the new anticoagulants. Therefore, particular awareness regarding these issues should be exercised.

\section{SUPPLEMENTARY MATERIAL}

Supplementary Table 1:

www.journals.cambridge.org/thc2013096

Supplementary Table 2:

www.journals.cambridge.org/thc2013097

Supplementary Figure 1:

www.journals.cambridge.org/thc2013098

Supplementary Table 3:

www.journals.cambridge.org/thc2013099

Supplementary Table 4:

www.journals.cambridge.org/thc2013100

Supplementary Table 5:

www.journals.cambridge.org/thc2013101

Supplementary Table 6:

www.journals.cambridge.org/thc2013102

Supplementary Figure 2:

www.journals.cambridge.org/thc2013103

Supplementary Figure 3:

www.journals.cambridge.org/thc2013104

\section{CONTACT INFORMATION}

Vida Hamidi, PhD Senior Health Economist; Norwegian Knowledge Centre for the Health Services, Oslo, Norway

Tove Ringerike, PHD Senior Researcher; Norwegian Knowledge Centre for the Health Services, Oslo, Norway 
Gunhild Hagen, M.Sc Senior Health Economist; Norwegian Knowledge Centre for the Health Services, Oslo, Norway Åsmind Reikvam, MD PhD FESC, Professor; Norwegian Knowledge Centre for the Health Services, Oslo, Norway Marianne Klemp, MD PhD, Research Director; Norwegian Knowledge Centre for the Health Services, Oslo, Norway

\section{CONFLICTS OF INTEREST}

All authors report they have no potential conflicts of interest.

\section{REFERENCES}

1. Kearon C. Duration of venous thromboembolism prophylaxis after surgery. Chest. 2003;124(Suppl):386S-392S.

2. Haas $\mathrm{S}$, Lassen MR. Venous thromboembolism after elective hip and knee replacemaent surgery. EJHPP Pract. 2010;16:17-19.

3. Ndegwa S, Moulton K, Argáez C. Dabigatran or Rivaroxaban versus other anticoagulants for thromboprophylaxis after major orthopedic surgery: Systematic review of comparative clinical-effectiveness and safety. Ottawa: Canadian Agency for Drugs and Technologies in Health; 2009.

4. Salazar CA, Malaga G, Malasquez G. Direct thrombin inhibitors versus vitamin $\mathrm{K}$ antagonists or low molecular weight heparins for prevention of venous thromboembolism following total hip or knee replacement. Cochrane Database Syst Rev (Online). 2010;4:CD005981.

5. Norwegian Medicine Agency. Preparatomtale. http://www.legemiddel verket.no/custom/Preparatsok/prepSearch__ 80333.aspx (accessed May 2011).

6. Norwegain Knowledge Centre for the Health Service. Slik oppsummerer vi forskning. [updated 2010; cited 2011 Mar 1]. http://www.kunnska pssenteret.no/Verkt\%C3\%B8y/Slik+oppsummerer+vi+forskning.2139. cms (accessed March 1, 2011).

7. Guyatt GH, Oxman AD, Kunz R, Vist GE, Falck-Ytter Y, Schunemann HJ. What is "quality of evidence" and why is it important to clinicians? BMJ. 2008;336:995-998.

8. Bjornara BT, Gudmundsen TE, Dahl OE. Frequency and timing of clinical venous thromboembolism after major joint surgery. J Bone Joint Surg Br. 2006;88:386-391

9. Dahl OE, Quinlan DJ, Bergqvist D, Eikelboom JW. A critical appraisal of bleeding events reported in venous thromboembolism prevention trials of patients undergoing hip and knee arthroplasty. J Thromb Haemost. 2010;8:1966-1975.

10. Prandoni P, Villalta S, Bagatella P, et al. The clinical course of deepvein thrombosis. Prospective long-term follow-up of 528 symptomatic patients. Haematologica. 1997;82:423-428.

11. Heit JA, Rooke TW, Silverstein MD, et al. Trends in the incidence of venous stasis syndrome and venous ulcer: A 25-year population-based study. J Vasc Surg. 2001;33:1022-1027.

12. Naess IA, Christiansen SC, Romundstad P, Cannegieter SC, Rosendaal FR, Hammerstrom J. Incidence and mortality of venous thrombosis: A population-based study. J Thromb Haemost. 2007;5:692-699.

13. Statistisk sentralbyrå. Befolkningsstatistikk. Døde. 2010. http://www. ssb.no/emner/02/02/10/dode/tab-2012-04-19-05.html (accessed 2011).

14. Wisløff T, Hagen G. Incorporating quality of efficacy documentation in health economic evaluations - Does it matter? Joint Colloquium of the Cochrane \& Campbell Collaborations 2010 and the 32nd Annual Meeting of the Society for Medical Decision Making 2010.

15. Prosjektgruppe hofte- og kneopererte. Områdeplan for rehabilitering. Sørlandet sykehus HF; 2010.
16. Norwegian Directorate of Health. Innsatsstyrt finansiering 2010. http:// helsedirektoratet.no/finansiering/isf/Sider/default.aspx (accessed 2011).

17. Pleym K, Sagerup L. Diagnostisering av dyp venetrombose ved kombinasjon av klinikk, D-dimer og ultralyd vener underekstremitet 2007.

18. Norwegian Labour and Welfare Administration. Forskrift om godtgjørelse av utgifter til helsehjelp som utføres poliklinisk ved statlige helseinstitusjoner og ved helseinstitusjoner som mottar driftstilskudd fra regionale helseforetak. http://www.nav.no/rettskildene/forskrift/F20071219-1761 (accessed 2011).

19. Bjorvatn A, Kristiansen F. Fondaparinux sodium compared with enoxaparin sodium: A cost-effectiveness analysis. Am J Cardiovasc Drugs. 2005;5:121-130.

20. Räsänen P, Paavolainen P, Sintonen H, et al. Effectiveness of hip or knee replacement surgery in terms of quality-adjusted life years and costs. Acta Orthop. 2007;78:108-115.

21. Haentjens P, De Groote K, Annemans L. Prolonged enoxaparin therapy to prevent venous thromboembolism after primary hip or knee replacement. A cost-utility analysis. Arch Orthop Trauma Surg. 2004;124: 507-517.

22. Lenert LA, Soetikno RM. Automated computer interviews to elicit utilities: Potential applications in the treatment of deep venous thrombosis. $J$ Am Med Inform Assoc. 1997;4:49-56.

23. Fenwick E, Claxton K, Sculpher M. Representing uncertainty: The role of cost-effectiveness acceptability curves. Health Econ. 2001;10:779-787.

24. Briggs A, Sculpher M, Claxton K. Decision modelling for health economic evaluation. New York: Oxford University Press; 2006.

25. Eriksson BI, Dahl OE, Buller HR, et al. A new oral direct thrombin inhibitor, dabigatran etexilate, compared with enoxaparin for prevention of thromboembolic events following total hip or knee replacement: The BISTRO II randomized trial. J Thromb Haemost. 2005;3:103-111.

26. RE-MOBILIZE Writing Committee, Ginsberg JS, Davidson BL, et al. Oral thrombin inhibitor dabigatran etexilate vs North American enoxaparin regimen for prevention of venous thromboembolism after knee arthroplasty surgery. J Arthroplasty. 2009;24:1-9.

27. Eriksson BI, Dahl OE, Rosencher N, et al. Oral dabigatran etexilate vs. subcutaneous enoxaparin for the prevention of venous thromboembolism after total knee replacement: The RE-MODEL randomized trial. J Thromb Haemost. 2007;5:2178-2185.

28. Eriksson BI, Dahl OE, Rosencher N, et al. Dabigatran etexilate versus enoxaparin for prevention of venous thromboembolism after total hip replacement: A randomised, double-blind, non-inferiority trial. Lancet. 2007;370:949-956.

29. Eriksson BI, Dahl OE, Huo MH, et al. Oral dabigatran versus enoxaparin for thromboprophylaxis after primary total hip arthroplasty (RE-NOVATE II). A randomised, double-blind, non-inferiority trial. Thromb Haemost. 2011;105:721-729.

30. Eriksson BI, Borris L, Dahl OE, et al. Oral, direct Factor Xa inhibition with BAY 59-7939 for the prevention of venous thromboembolism after total hip replacement. J Thromb Haemost. 2006;4:121-128.

31. Eriksson BI, Borris LC, Dahl OE, et al. A once-daily, oral, direct Factor Xa inhibitor, rivaroxaban (BAY 59-7939), for thromboprophylaxis after total hip replacement. Circulation. 2006;114:2374-2381.

32. Lassen MR, Ageno W, Borris LC, et al. Rivaroxaban versus enoxaparin for thromboprophylaxis after total knee arthroplasty. $N$ Engl J Med. 2008;358:2776-2786.

33. Eriksson BI, Borris LC, Dahl OE, et al. Dose-escalation study of rivaroxaban (BAY 59-7939)-an oral, direct Factor Xa inhibitor-for the prevention of venous thromboembolism in patients undergoing total hip replacement. Thromb Res. 2007;120:685-693.

34. Stevenson M, Scope A, Holmes M, Rees A, Kaltenthaler E. Rivaroxaban for the prevention of venous thromboembolism: A single technology appraisal. Health Technol Assess. 2009;13(Suppl 3):43-48. 
35. Turpie AG, Lassen MR, Davidson BL, et al. Rivaroxaban versus enoxaparin for thromboprophylaxis after total knee arthroplasty (RECORD4): A randomised trial. Lancet. 2009;373:1673-1680.

36. Kakkar AK, Brenner B, Dahl OE, et al. Extended duration rivaroxaban versus short-term enoxaparin for the prevention of venous thromboembolism after total hip arthroplasty: A double-blind, randomised controlled trial. Lancet. 2008;372:31-39.

37. Kahn SR, Ginsberg JS. Relationship between deep venous thrombosis and the postthrombotic syndrome. Arch Intern Med. 2004;164:17-26.

38. Botteman MF, Caprini J, Stephens JM, et al. Results of an economic model to assess the cost-effectiveness of enoxaparin, a low-molecular-weight heparin, versus warfarin for the prophylaxis of deep vein thrombosis and associated long-term complications in total hip replacement surgery in the United States. Clin Ther. 2002;24:1960-1986.

39. McCullagh L, Tilson L, Walsh C, Barry M. A cost-effectiveness model comparing rivaroxaban and dabigatran etexilate with enoxaparin sodium as thromboprophylaxis after total hip and total knee replacement in the irish healthcare setting. Pharmacoeconomics. 2009;27:829-846.

40. Wolowacz SE, Roskell NS, Maciver F, et al. Economic evaluation of dabigatran etexilate for the prevention of venous thromboembolism af- ter total knee and hip replacement surgery. Clin Ther. 2009;31:194212.

41. Oslo kommune. Verbalvedtak 4 vedr. hjemmetjenesten. 2009. Report No.: BU-sak 41/2009.

42. NHO SERVICE. HELSE OG OMSORG; Suksessfaktorer for kjøp av helse- og omsorgstjenester. 2009. http://www.nhoservice.no/getfile. php/Filer/Publikasjoner/Omsorgbrosjyre2009.pdf (accessed January 23, 2011).

43. Offord R, Lloyd AC, Anderson P, Bearne A. Economic evaluation of enoxaparin for the prevention of venous thromboembolism in acutely ill medical patients. Pharm World Sci. 2004;26:214-220.

44. Ashrani AA, Heit JA. Incidence and cost burden of post-thrombotic syndrome. J Thromb Thrombolysis. 2009;28:465-476.

45. Eriksson BI, Borris LC, Friedman RJ, et al. Rivaroxaban versus enoxaparin for thromboprophylaxis after hip arthroplasty. $N$ Engl $J$ Med. 2008;358:2765-2775.

46. Turpie AG, Fisher WD, Bauer KA, et al. BAY 59-7939: An oral, direct factor $\mathrm{Xa}$ inhibitor for the prevention of venous thromboembolism in patients after total knee replacement. A phase II dose-ranging study. $J$ Thromb Haemost. 2005;3:2479-2486. 